\title{
Debates, tensões e compromissos na institucionalização da Economia Social em Portugal, 1974-2013 ${ }^{1}$
}

\author{
Álvaro Garrido ${ }^{2}$
}

\begin{abstract}
RESUMO
O presente artigo proporciona uma breve análise do processo histórico de institucionalização da Economia Social e das políticas de solidariedade concretizadas em Portugal desde a Revolução de Abril de 1974 à publicação da Lei de Bases da Economia Social, em 2013. Tomando por referência o conceito que o ordenamento jurídico português tem fixado, a análise centra-se nas relações institucionais e ideológicas que se estabeleceram, a partir de 1974 e da Constituição de 1976, entre as políticas sociais públicas instituídas pela Democracia e a acção das organizações identificadas com a Economia Social e Solidária. Apresentam-se os marcos fundamentais desse relacionamento negocial e destacam-se os significados dos compromissos estabelecidos. A análise assenta numa perspectiva sistémica e institucionalista que não dispensa referências ao jogo de poderes e à dinâmica dos interesses. Neste como noutros campos que implicam a justiça social e a democracia económica, o caso português oferece um bom exemplo da forma como as práticas voluntárias de solidariedade e de cooperação beneficiaram muito da institucionalização do Estado-Providência.
\end{abstract}

Palavras-chave: Economia Social; solidariedade; políticas sociais, Portugal; democracia.

Debates, tensions and commitments on the institutionalization of Social Economy in Portugal, 1974-2013

\begin{abstract}
This article provides a brief analysis on the historical process of the institutionalization of Social Economy and solidarity policies achieved in Portugal from the April 1974's Revolution to the publication of the Social Economy Basis Law, in 2013. Considering the concept established in the Portuguese Law, the article is focused on the institutional and ideological relations that were established, since 1974 and from the Democratic Constitution of 1976, between the public social policies achieved by Democracy and the action of the institutions related with Social and Solidary Economy. We put in evidence the fundamental remarks of that negotiated relation and we point out the meaning of the commitments that were accomplished. The analysis is based in a systemic and institutionalist approach that doesn't release references to the powers play and the dynamic of interests. In this and other issues that entailed social justice and economic democracy, the Portuguese case shows a relevant example on how the voluntary practices for solidarity and cooperation benefited with the institutionalization of the Welfare State.
\end{abstract}

Key words: Social Economy; solidarity; social policies; Portugal; democracy.

\section{INTRODUÇÃO}

No final dos anos setenta do século XX, em diversos países da Europa e noutras

\footnotetext{
${ }^{1}$ Este artigo antecipa informação reunida no livro de Álvaro Garrido e David Pereira, A Economia Social em Movimento: uma história das organizações, Lisboa, Tinta da China, 2018 (no prelo).

${ }^{2}$ Professor Associado com Agregação. Faculdade de Economia da Universidade de Coimbra, Portugal.

Email: agarrido@fe.uc.pt
} 
partes do mundo, a ideia de Economia Social voltou a ser reivindicada. Por esses anos a expressão conheceu uma vitalidade apenas comparada à que tivera por volta de 1900, na viragem do século, quando a "ideia nova" se apresentou na Exposição Universal de Paris e sobressaiu num pavilhão de ideias e de práticas reformistas da sociedade. Sobranceiro ao rio Sena, o pavilhão foi chamado de "Palais de l'Économie Sociale" e o seu comissário foi Charles Gide, um cooperativista protestante e de ideias social-cristãs, considerado o "pai da Economia Social" (HORNE, 2004, 11-37; GARRIDO, 2016, 36-48).

Em finais do século XIX, em diversos países mais e menos industrializados, na economia e na sociedade, muitas entidades colectivas votadas à produção de bens e serviços já invocavam princípios de Economia Social. Depois de um longo refluxo, na segunda metade do século XX, em nações como a França, a Itália e a Bélgica, não tardou que a Economia Social oferecesse soluções organizativas complementares dos sistemas públicos de protecção social e que depressa fosse reconhecida pelo Estado, nomeadamente como produtora de serviços e de emprego (LAVILLE, 2018, 185). No caso português, depois da Revolução de Abril de 1974 registou-se até uma notória singularidade: às organizações da Economia Social mais vocacionadas para fins de solidariedade (assistência social ou acção social directa) o Estado atribuiu um papel de relevo nas políticas de assistência e de segurança social. As respostas sociais privadas foram articuladas com o papel das instituições e políticas públicas segundo uma lógica de cooperação institucionalizada e de pendor neocorporativo (BRANCO, 2017, 534-558; FERREIRA et alia, 2016, 71-97).

$\mathrm{Na}$ década de setenta, a crise económica internacional associada aos choques petrolíferos e o retorno das ideias económicas liberais à política económica dos Estados e organizações internacionais (FRIEDDEN, 2006, 363-385) explicam a redescoberta da Economia Social, o revigoramento dos seus significados e das suas práticas. Num contexto em que se conjugaram múltiplas crises que resultaram na contestação dos modelos de EstadoProvidência que haviam nascido depois da II Guerra Mundial e que despertaram um acerado neoliberalismo, a revalorização de outras modalidades de protecção social e de outros modelos de organização da vida económica abriu caminho a diversas formas de Economia Social.

É certo que o conceito não regressou debaixo de uma formulação unívoca e consensual. Pelo contrário, as suas acepções e práticas foram mais diversas do que nunca e nem sempre convergentes. Também por isso, volvidos poucos anos as próprias entidades da Economia Social procuraram formas e expressões de convergência e um reconhecimento 
institucional que abriu uma nova era na sua relação histórica com o Estado e com o próprio mercado (LAVILLE, 2018, 83-100).

A maioria dos autores atribui o longo adormecimento da Economia Social, muito evidente durante boa parte do século XX, dos anos vinte aos anos setenta, à turbulência dramática das guerras mundiais e ao nascimento e consolidação dos Estados-Providência de inspiração keynesiana. Se a política social dos fascismos dispensara e reprimira o recurso a formas particulares de protecção social e a quaisquer práticas de democracia económica, tal como sucedeu no Estado Novo de Salazar e Caetano, a institucionalização de sistemas redistributivos de protecção social também lhes deixou pouca margem (GARRIDO, 2016, 198-218).

Outros especialistas tendem a desvalorizar os efeitos dessas razões de contexto, dado que a Economia Social já perdera expressão nas primeiras décadas do século XX. O declínio acontecera quer devido ao avanço dos sistemas de seguro social obrigatório em diversos países europeus, quer porque a Economia Social se partira em famílias demasiado especializadas e pouco articuladas entre si. A violência dos fascismos e a hostilidade desses regimes a expressões auto-organizadas de protecção social e a formas de economia desinseridas do Estado também explicam a longa dormência da Economia Social e a marginalização das suas práticas e organizações.

No contexto das crises do capitalismo que atravessaram a década de setenta, foi muito comum o movimento de retorno a formas locais e auto-gestionárias de organização da economia e da sociedade. Houve expressões concretas dessas dinâmicas em inúmeros países europeus, da América do Sul e do continente africano (SINGER, 2018, 11-13). O desenvolvimento local de base associativa tornou-se uma tendência vigorosa, assim como a emergência de organizações sociais sem fins lucrativos (LAVILLE, 2018, 11-16).

Portugal destacou-se pela natureza dos compromissos constitucionais estabelecidos na transição para a democracia, que dispensaram, desde logo na Constituição democrática de 1976, um papel fundamental ao cooperativismo e que, por um lado, abriram caminho aos desenvolvimentos do sector solidário da Economia Social (laico e religioso), por outro. Na história desses caminhos que se bifurcam reside uma boa parte da história recente da Economia Social. 


\section{PORTUGAL, A DEMOCRACIA E O RECONHECIMENTO DA ECONOMIA SOCIAL}

Em Portugal, as especificidades do processo histórico retardaram o acompanhamento das dinâmicas europeias, mas a redescoberta da Economia Social não deixou de acontecer e de encontrar um claro reconhecimento institucional. A queda da interminável ditadura corporativista de Salazar e Caetano (1932-1974) e a construção tardia de um Estado-Providência democrático em Portugal, em 1974-76, coincidiram no tempo com a redescoberta da Economia Social no espaço europeu.

A afirmação das organizações e práticas identificadas com a Economia Social ocorreu por influência quer dos movimentos sociais associados ao processo revolucionário de 1974, entre os quais se destacaram o cooperativismo e o associativismo de base popular, quer por estímulo dos sistemas públicos de provisão de bens e serviços sociais que Portugal criou entre 1974 e $1979^{3}$.

A relação que se estabeleceu entre o Estado-Providência democrático e a Economia Social esteve longe de traduzir um jogo de soma nula. A criação de um sistema público e universal de protecção social estimulou as mutualidades, misericórdias e algumas associações a desenvolver uma actividade complementar no domínio da segurança social e da acção social directa, em particular no campo da assistência. Os movimentos de estímulo foram recíprocos - do Estado para a sociedade civil e o seu contrário - e desenvolveram-se em diversos sentidos, mas acabaram por incentivar o papel das organizações da Economia Social no seu conjunto. Historicamente, só na I República (1910-1926) se verificara, de forma tão notória e contundente, essa influência recíproca entre as instituições do EstadoProvidência e as entidades da Economia Social (PEREIRA, 1999, 45-61).

Depois do 25 de Abril de 1974, essa relação dialéctica voltou em força. Em domínios como a saúde, a nacionalização estatal de serviços e de equipamentos hospitalares, decidida pelo III Governo provisório de Vasco Gonçalves em Dezembro de 1974 ${ }^{4}$, obrigou as mutualidades e as misericórdias a procurarem outras áreas de actividade e a adaptarem os seus perfis. O próprio Estado e as políticas sociais que decorreram dos compromissos constitucionais estimularam a afirmação e o crescimento de um sector solidário da Economia Social. A institucionalização da Democracia trouxe consigo uma profunda transformação da Economia Social que resultou na inclusão das suas entidades nas políticas sociais públicas.

\footnotetext{
3 Em 1979 concretizou-se a criação do Sistema Nacional de Saúde, uma das criações institucionais mais admiráveis da democracia portuguesa nascida em 1974. Lei n. ${ }^{\circ}$ 56/79, de 15 de setembro.

${ }^{4}$ Decreto-Lei 704/74, de 7 de Dezembro.
} 
Alguns compromissos institucionais selaram essa relação de parceria.

A partir de Abril de 1974, o desenvolvimento fulgurante do movimento cooperativo, das associações populares e de um renovado cooperativismo socialista e autogestionário foram acompanhados de um reposicionamento das misericórdias e das mutualidades, instituições muito antigas e reconhecidas pelas comunidades locais. Esse duplo movimento, de "revolução" e "reacção", traduz bem as tensões políticas e sociais do processo revolucionário e a criação dos pilares institucionais de um Estado-Providência democrático que, pela primeira vez, erigiu sistemas públicos de provisão de bens e serviços sociais nas áreas da segurança, social, saúde e educação. Por contraditório que pareça, a criação de um Estado-Providência e de um sistema público de segurança social vinculado a direitos sociais inscritos na Constituição favoreceu a Economia Social e estimulou o desenvolvimento, no seu âmbito, de organizações de vocação solidária.

De 1976 em diante, no ano em que foi publicada a Constituição democrática portuguesa, a Economia Social foi não apenas aquilo que quis ser e o que resultou das suas próprias dinâmicas. Foi também aquilo que pôde ser, no sentido em que as suas entidades tiveram de reagir à institucionalização das políticas sociais do Estado e aos próprios ciclos económicos. O espaço socioeconómico disputado pelas organizações de vocação solidária e a natureza dos seus estatutos dependeram muito desse equilíbrio e das suas veredas. A ebulição organizativa da Economia Social e a forma como se estruturaram as suas entidades e "famílias", em especial a dicotomia entre o sector mercantil e o sector solidário (não mercantil) e entre o campo laico e o religioso, exprimem uma forte dependência relativamente às políticas públicas e ao posicionamento político dos governos.

O reconhecimento de um "sector cooperativo e social" na Constituição democrática de 1976 significou a afirmação de um princípio de coexistência de três sectores de propriedade (público, privado e "cooperativo e social”) que conferiu à Economia Social um substrato jurídico explícito, sólido e autónomo. Tratou-se de uma típica garantia constitucional (MEIRA, 2013, 5). A vertente cooperativa enunciada na Constituição abrangia todo o subsector cooperativo da Economia Social, então em pleno crescimento; por sua vez, o campo social incluía os subsectores autogestionário, o comunitário e o solidário, este último em franco desenvolvimento anos mais tarde.

A Constituição não se limitou a discriminar positivamente a Economia Social. Além disso, inscreveu no espaço jurídico português um claro princípio de protecção do sector cooperativo e social prevendo logo aí a tomada de medidas que facilitassem o seu 
desenvolvimento. Não havia uma identificação plena entre Economia Social e o "sector cooperativo e social", dado que algumas entidades que estavam fora daquele sector, não deixariam de integrar a Economia Social (NAMORADO, 2007, 10-12). Era o caso das associações que não prosseguiam fins de solidariedade social e das fundações.

Em Portugal, o papel da Economia Social nas políticas sociais públicas conheceu, mais tarde, outro pilar fundamental: a Lei de Bases da Segurança Social, publicada em 1984. Significativamente, quer a Constituição quer a Lei de Bases resultaram de uma acalmação política construída ao centro do sistema político.

A herança ditatorial pesou muito na configuração das dinâmicas de redescoberta e afirmação da Economia Social. Seja porque suscitou o preenchimento dos imensos vazios que havia em termos de respostas sociais, seja por apuramento de práticas e instituições que vinham desse período e que tinham uma especial robustez organizativa, a exemplo das misericórdias. Vejamos como evoluiu o posicionamento das principais entidades da Economia Social no período que se seguiu à Revolução de Abril e que formas de institucionalização encontraram as suas organizações.

\section{AS COOPERATIVAS}

Na sua concepção de democracia directa, participativa e verdadeiramente popular, construída na oposição ao salazarismo, o intelectual socialista António Sérgio (1883-1969) imaginara um cooperativismo capaz de promover a emancipação da grei. Liberto da opressão autoritária do Estado Novo e beneficiando da vontade revolucionária de instaurar uma sociedade socialista, o cooperativismo tomou na Constituição portuguesa de 1976 um lugar semelhante ao dos grandes problemas nacionais (NAMORADO, 2013, 50), tanto quanto as liberdades e os direitos sociais de cidadania.

Henrique de Barros (1904-2000), notável cooperativista e engenheiro agrónomo, foi o presidente eleito da Assembleia Constituinte, facto que também pesou no reconhecimento atribuído ao sector cooperativo, cuja expressão social conheceu uma extraordinária afirmação nos anos que se seguiram à Revolução. Enquanto Ministro de Estado do I Governo Constitucional presidido por Mário Soares, Henrique de Barros criou o Instituto António Sérgio do Sector Cooperativo (INSCOOP), em $1976^{5}$, organismo que teve um papel

\footnotetext{
${ }^{5}$ Decreto-Lei no 902/76, de 31 de Dezembro. O INSCOOP funcionava no âmbito da Presidência do Conselho de Ministros.
} 
fundamental no fomento das associações cooperativas.

A criação do INSCOOP teve por objectivo dar apoio técnico a uma realidade cooperativa fulgurante e em pleno desenvolvimento. Durante o PREC (Processo Revolucionário em Curso) e nos anos seguintes, o desenvolvimento das leis e instituições dificilmente acompanhava as dinâmicas do movimento cooperativo. Em 1976 havia 1588 cooperativas registadas e em 1978 já eram 3078, ou seja, quase duplicaram. Em 1995 a esmagadora maioria ainda eram cooperativas agrícolas (31\%); o segundo ramo mais expressivo encontrava-se na habitação e construção (15\%); o terceiro pertencia aos serviços (14\%); e o quarto correspondia às cooperativas de consumo $(9 \%)^{6}$. De Abril de 1974 a finais de 1976 foram legalizadas em Portugal cerca de mil cooperativas.

Devido à natureza ambígua de numerosas cooperativas agrícolas que transitaram do contexto ditatorial, a influência do cooperativismo agrícola nos novos tempos foi difusa. Ainda assim, depois de 1976, as unidades colectivas de produção (UCP) associadas à Reforma Agrária foram registadas como cooperativas de produção (BARRETO, 2017, 328-334; VARELA E PIÇARRA, 2016, 1189-1218). Antes disso os governos adiaram sempre a definição jurídica das UCP, alegando que era indispensável apoiá-las.

As UCP tinham vários pontos em comum com as cooperativas, em especial a auto-organização e a ausência de capital societário. Mas nunca dispensaram o pagamento de salários aos trabalhadores e entre 1975 e 1977 - precisamente até à "Lei Barreto"7 - receberam crédito estatal em volumes consideráveis. De início, o Estado reconheceu as UCP e aproximou o seu estatuto das cooperativas. No entanto, a legislação que deu abrigo às expropriações de terras e ao controlo de gados e equipamentos mecânicos deixou claras as diferenças e impediu que a Constituição as identificasse com as cooperativas (BARRETO, 2017, 331).

Em 1976, com a mudança política que ocorre e com o PS de Mário Soares empenhado em promover uma clara distinção entre colectivismo e cooperativismo, o curso das UCP altera-se. Nos termos da Constituição aprovada em 1976, as UCP passaram a fazer parte inequívoca do sector público da economia, ao passo que as cooperativas integravam um sector

\footnotetext{
${ }^{6}$ Cálculos obtidos a partir de dados colhidos em Anuário Comercial do Sector Cooperativo, Lisboa, INSCOOP. ${ }^{7}$ Lei 77/77, aprovada pelo Parlamento a 22 de Julho de 1977 (I Governo Constitucional presidido por Mário Soares) pôs termo às ocupações colectivas de terrenos agrícolas e culminou na devolução das herdades alentejanas aos anteriores proprietários. A "Lei Barreto", como ficou conhecida, consistiu numa resposta política à Lei da Reforma Agrária (Decreto-Lei n 406-A/75, de 29 de Julho de 1975) que determinara a expropriação e nacionalização das grandes propriedades agrícolas e que dera cobertura e incentivo a um amplo movimento de ocupações de terras e de herdades.
} 
especial: o "sector cooperativo e social". As terras das UCP eram propriedade do Estado e os bens pertenciam aos colectivos de trabalhadores.

Além dos factores de estímulo à criação de cooperativas envolvidas nos projectos revolucionários de colectivismo agrário, o retorno de centenas de milhar de pessoas das colónias africanas também se revelou importante. Muitos portugueses que regressaram de Angola e Moçambique conheciam bem a realidade cooperativa e as suas práticas, em especial as cooperativas de consumo e as de habitação. Durante o PREC e nos anos seguintes o movimento cooperativo foi particularmente intenso nos sectores da habitação e da educação.

$\mathrm{Na}$ educação, houve dois movimentos fortes: muitos colégios particulares transformaram-se em cooperativas de ensino; e por iniciativa de pais e encarregados de educação de crianças com deficiência, em 1975 surgiu em Lisboa a primeira CERCI (Cooperativa para a Educação e Reabilitação de Crianças Inadaptadas, segundo a designação original, actualmente Cooperativa de Educação e Reabilitação de Cidadãos com Incapacidade).

A criação das CERCI é muito significativa das dinâmicas dos movimentos sociais deste período. Em 1996, aquando da revisão do Código Cooperativo, as CERCI passaram a ser a cooperativas de solidariedade social e tomaram o estatuto de entidades equiparadas a IPSS (Instituições Particulares de Solidariedade Social).

Não obstante os desenvolvimentos que houve em áreas específicas da solidariedade e no seu conjunto, em Portugal as dinâmicas de revitalização da Economia Social começaram pelo movimento cooperativo. Foi dele que, na maioria dos casos, nasceram organizações e práticas que ganharam robustez nos movimentos sociais e tomaram, depois, formas organizativas de natureza solidária e outras.

De 1976 a 1980 o movimento cooperativo conheceu grandes mudanças e um crescimento que não esteve isento de flutuações. As cooperativas agrícolas eram o ramo mais estruturado do movimento cooperativo, mas conheceram algum refluxo na sequência da "Lei Barreto" porque perderam apoios financeiros e enfrentaram privatizações.

De certa forma, a experiência da Reforma Agrária vinculou o cooperativismo agrícola às experiências colectivistas, acabando por projectar sobre o cooperativismo um ónus ideológico que persistiu na memória colectiva e nos próprios debates institucionais. 
Gráfico 1- Cooperativas, 1974-2009.

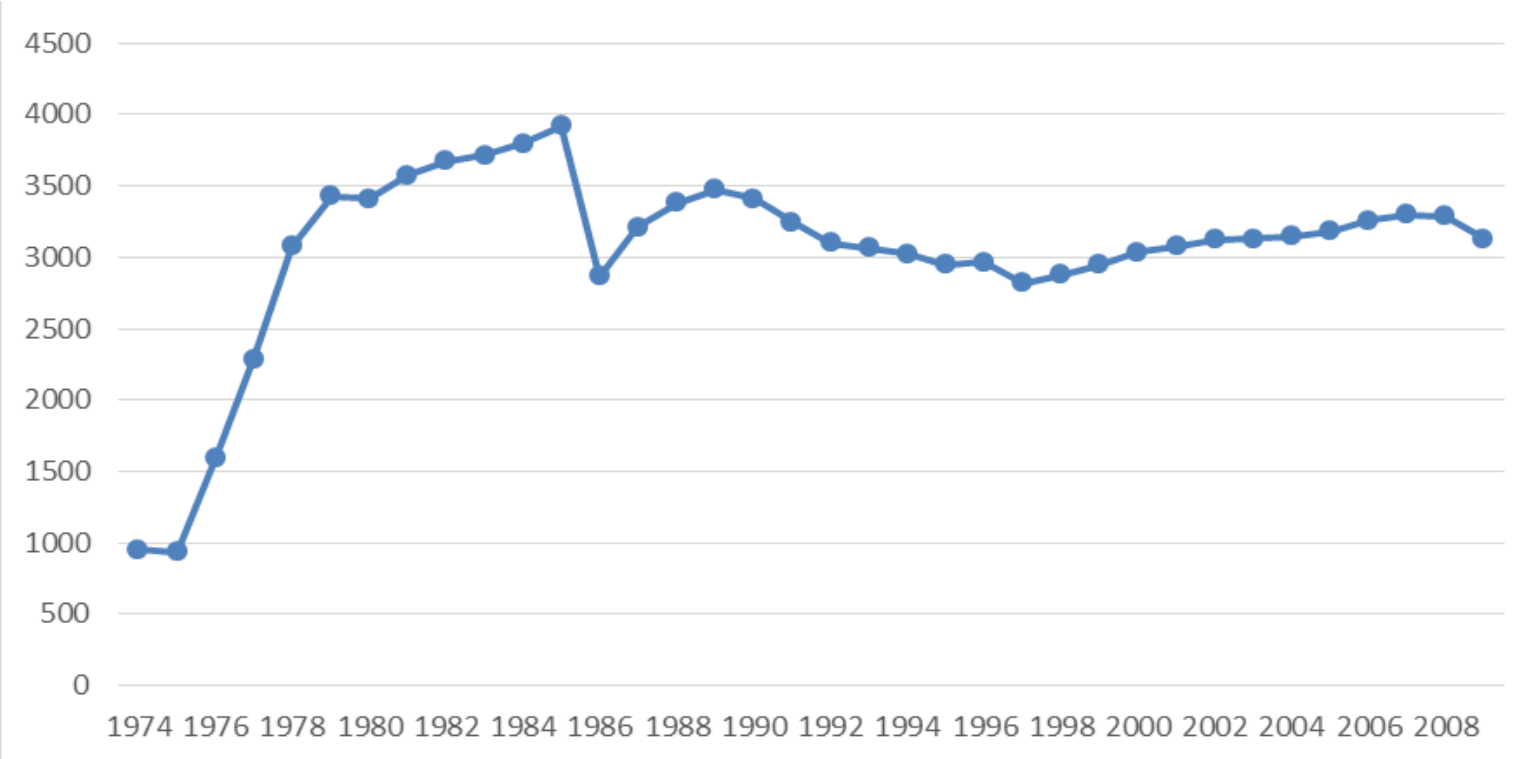

Fontes: Inácio Rebelo de Andrade, O Instituto António Sérgio e a Formação Cooperativa, Lisboa, Instituto António Sérgio do Sector Cooperativo, 1978; Anuário Comercial do Sector Cooperativo, Lisboa, INSCOOP, 1987-2008; João Carlos Pereira Bastos, As cooperativas depois de Abril: uma força dos trabalhadores, Coimbra, Centelha, 1977; João Salazar Leite, Cooperação e Intercooperação, Lisboa, Livros Horizonte, 1982; AA.VV., Cooperativismo, Emprego e Economia Social (edição de Carlos Pestana Barros e J. C. Gomes Santos), Lisboa, Vulgata, 1999. Observações: Considerámos o número de organizações recenseadas.

Em 1985, nas vésperas da adesão de Portugal à Comunidade Económica Europeia o movimento cooperativo era uma realidade muito diversificada e numerosa, composta por 3917 organizações, descontando aquelas que estariam inactivas. Um ano depois, contavam-se muito menos unidades, apenas 2867, ainda que em 1989 já se registasse uma recuperação parcial: nesse ano já havia 3475 cooperativas.

A quebra acentuada que se registou em 1986 deve-se ao arrefecimento do contexto político-social da Revolução e, sobretudo, ao impacto da adesão à Comunidade Europeia e à entrada em vigor das políticas comuns. A quebra do número de cooperativas acusa a necessidade que houve de desarmar práticas pouco compatíveis com a lógica concorrencial de mercado, em especial na agricultura e na pesca.

$\mathrm{Na}$ área do crédito agrícola e das cooperativas de produção agrícola houve, porém, desenvolvimentos importantes, em boa parte induzidos pela integração europeia. A adesão de Portugal à CEE e as negociações que a antecederam levantaram de imediato o problema da representação em Bruxelas da agricultura organizada em cooperativas. A CONFRAGRI (Confederação Nacional das Cooperativas Agrícolas e do Crédito Agrícola de Portugal), que hoje agrupa nove federações sectoriais de âmbito nacional incluindo numerosas cooperativas de empresas agrícolas e as caixas de crédito agrícola, foi constituída a 3 de Outubro de 1985. 
Havia que preparar a adesão e era necessário encontrar uma mediação institucional entre o Estado e o sector cooperativo da agricultura portuguesa de forma a implantar a Política Agrícola Comum e a tirar partido dos seus instrumentos financeiros, em especial nas políticas de mercados e preços e na formação técnica.

Se o Código Cooperativo de 1980 já aproximara a gestão das cooperativas agrícolas da economia de mercado e das políticas de fomento, o regime jurídico do crédito agrícola e das cooperativas de crédito agrícola mútuo aprovado em $1982^{8}$, revelou-se um progresso importante. Em especial, porque desvinculou o financiamento das caixas de crédito agrícola da Caixa Geral de Depósitos que, durante o Estado Novo, exercera sobre as cooperativas de crédito agrícola uma tutela asfixiante.

Feito esse caminho de inserção do cooperativismo agrícola no contexto institucional da Política Agrícola Comum (PAC) e desfeita a herança das experiências ligadas à reforma agrária, a CONFAGRI protagonizou, juntamente com a Confederação dos Agricultores de Portugal e o Instituto Nacional de Intervenção e Garantia Agrícola, políticas de cooperação institucionalizada para implementação das regras da PAC nos diversos subsectores e produtos, incluindo o ramo agro-alimentar. Como era comum em múltiplas áreas das políticas públicas dessa época, o modelo era claramente neocorporativo na medida em que articulava as funções do Estado com os interesses de grupos socioprofissionais. Essa parceria encontra-se estabilizada e exprime princípios e finalidades semelhantes aos do sistema de cooperação institucional que existe na área da solidariedade social.

\section{AS INSTITUIÇÕES PARTICULARES DE SOLIDARIEDADE}

A Constituição Portuguesa de 1976 deixou bem claro que todos os cidadãos "têm direito à segurança social” (art. ${ }^{\circ}$ 63. ${ }^{\circ}$, n. $^{\circ}$ 1), pertencendo "ao Estado organizar, coordenar e subsidiar um sistema de segurança social unificado e descentralizado" (art. ${ }^{\circ} 63 .^{\circ}, \mathrm{n}^{\circ}{ }^{\circ}$ ).

Esta formulação de natureza geral sobreviveu aos vários processos de revisão e já apontava para o princípio da protecção social universal. Logo na primeira versão da Constituição democrática, o "direito à segurança social" era apresentado como incondicional, um direito social a ser garantido a todos os cidadãos, em quaisquer circunstâncias, tal como a saúde e a educação. O mesmo artigo constitucional também afirmava que "a organização do sistema de segurança social não prejudicará a existência de instituições privadas de

\footnotetext{
${ }^{8}$ Decreto-Lei n. ${ }^{\circ} 231 / 82$ de 17 de Junho.
} 
solidariedade social não lucrativas" (art. ${ }^{\circ} 63$, n. ${ }^{\circ 3}$, CRP 1976). Significa que a Economia Social, especialmente o seu sector solidário, já era entendida como um parceiro relevante das políticas públicas, num plano de compromisso ou em parceria com o Estado, de forma a garantir a concretização de funções de previdência e assistência (FERREIRA et alia, 2016, 71-97).

A natureza categórica da expressão constitucional que acabámos de sublinhar parecia significar uma abertura sistémica. Além disso, a formulação preventiva de um princípio de subsidiariedade permitiria reconhecer e valorizar o papel de estruturas sociais intermédias, sobretudo da Igreja Católica.

Ainda que o estatuto das organizações da Economia Social tenha conhecido entretanto diversas alterações, quer por deliberação própria e numa clara afirmação de princípios, quer por necessidade de adaptação às leis e instituições públicas de Segurança Social, é notório que esse quadro de cooperação com as estruturas sociais intermédias e autoorganizadas não conheceu mudanças de vulto nas sucessivas revisões constitucionais, de 1982 a 2005. A revisão constitucional de 1982 até especificou que "as instituições particulares de solidariedade não lucrativas" - é essa a expressão utilizada, num momento em que se preparava a redefinição do estatuto das IPSS - teriam um papel fundamental na criação de redes de assistência materno-infantil, na abertura de creches e de estruturas de apoio à infância e à juventude, no incremento de uma política para a terceira idade e no apoio a pessoas com deficiência.

Reactualizando os princípios constitucionais de 1976, o sistema público de protecção social dispensava um papel cada vez mais explícito, aberto e não apenas supletivo, às entidades da Economia Social. Por vontade política de diversos governos, com especial empenho das coligações governamentais de centro-direita e de centro-esquerda, à Economia Social foi reservada a componente de assistência do sistema público de protecção social. Já na saúde, a Constituição não abriu espaço ao sector associativo.

O papel de complementaridade atribuído pelo Estado às organizações associativas na área da protecção social foi confiado a um amplo conjunto de equipamentos e de organizações a que corresponde o subsector solidário (não contributivo e não mercantil) da Economia Social. A participação dessas numerosas organizações nas políticas sociais do Estado (todas elas dotadas do estatuto de IPSS, incluindo as cooperativas de solidariedade social ou equiparadas a IPSS) concretizar-se-ia por meio da transferência de competências e de recursos nas áreas da educação (pré-escolar) e da assistência a grupos vulneráveis 
(deficientes, crianças e idosos).

O Estatuto das IPSS foi aprovado e publicado em finais de 1979, por iniciativa do “Governo dos cem dias" presidido por Maria de Lurdes Pintassilgo, uma carismática militante social-católica (FERREIRA, 2000, 274-278). As IPSS passavam a ser a expressão organizada do dever constitucional de solidariedade colectiva e dignidade da pessoa humana. Nesse ano foi reconhecida a existência de 1271 IPSS, um conjunto de instituições muito diversas entre si, do associativismo popular às misericórdias e mutualidades, universo que cresceu muito nos anos seguintes (FERREIRA, 2000, 279). Em 2001 já eram 3200 e em 2005 já passavam de 4000 (JOAQUIM, 2012, 13; BRANCO, 2017, 548).

Associadas as IPSS ao sistema público de segurança social, os acordos de cooperação tornavam-se um instrumento fundamental e vinculativo de atribuição contratualizada de verbas às instituições particulares. Actualmente, com uma cadência bienal o modelo de cooperação previsto na lei é reactivado mediante a celebração de um acordo de cooperação entre o Estado e os representantes das IPSS. Essa rede de entidades e de instituições integra, por direito próprio e em estrita colaboração com os serviços públicos, o sistema público de protecção social. Estabeleceu-se assim um sistema de cidadania social que confiou às IPSS funções decisivas de solidariedade e assistência, compromisso que configura um modelo de Estado social assente num triângulo distorcido: Estado, mercado, famílias.

\section{AS MISERICÓRDIAS}

Em 1974, a importância das misericórdias era imensa e claramente atestada pelo reconhecimento da acção das santas casas nas comunidades locais. Quando se deu a Revolução de 25 de Abril, à excepção dos hospitais centrais de Lisboa, Coimbra e Porto e salvo os hospitais militares, toda a restante rede hospitalar distrital e concelhia estava confiada às misericórdias (PAIVA, 2010, 8).

Os anos do PREC foram especialmente difíceis para as misericórdias na medida em essas instituições foram identificadas com o Estado Novo e com a natureza autoritária do corporativismo assistencialista. No tumulto revolucionário, muitas misericórdias tiveram instalações ocupadas e outras viram as mesas directivas ocupadas por trabalhadores e pressionadas a assumirem, também elas, formas autogestionárias de governo. O grande momento de viragem e de problemas para as misericórdias coincidiu com a "nacionalização dos hospitais". 
Através do Decreto-Lei no 704/74, de 7 de Dezembro de 1974, Vasco Gonçalves decidiu que os hospitais centrais e distritais administrados pelas misericórdias passavam a integrar a rede nacional de hospitais. Cerca de um ano depois, o Governo estendeu a medida aos hospitais concelhios. Confirmavam-se e aprofundavam-se as tendências de uniformização do sistema de saúde e de assistência já esboçadas no marcelismo, ainda que esses precedentes não tivessem qualquer vinculação a direitos sociais universais ${ }^{9}$.

Durante os tempos que se seguiram, a reacção enérgica das misericórdias e o compromisso de interesses que se estabeleceu com a hierarquia eclesiástica foi um processo decisivo na recomposição das relações com o Estado e de crescente aproximação das misericórdias ao espaço organizativo da Economia Social. A convergência das misericórdias com as demais entidades da Economia Social começou por ser reactiva e nunca se mostrou incondicional.

Poucos meses depois de aprovada a Constituição democrática de 1976, em novembro realizou-se em Viseu o V Congresso Nacional das Misericórdias, um acontecimento importante e pleno de significados políticos. Volvidas as anteriores tentativas para se criar uma federação das misericórdias ou um organismo semelhante que as unisse, um grupo de provedores de misericórdias unidos pela indignação provocada pela nacionalização dos hospitais, apelam à união das santas casas e à defesa da identidade e autonomia das misericórdias em geral. No desassombrado congresso de Viseu, seguido atentamente pela Conferência Episcopal, e que contou com a participação directa de alguns bispos e ministros do I Governo Constitucional, foi deliberado por unanimidade e aclamação criar a União das Misericórdias Portuguesas (SÁ E LOPES, 2008, 119-122).

O congresso de 1976 foi o momento fundador dos valores fundamentais da União: autonomia e responsabilidade na cooperação com o Estado, com a Igreja e a sociedade ${ }^{10}$. Na opinião de Mariano Cabaço, dirigente da União das Misericórdias, antes do Congresso de 1976 essas instituições de assistência e caridade "estavam perdidas (...). Vários provedores mobilizaram-se contra a nacionalização dos hospitais, uma decisão precipitada dos governos

\footnotetext{
${ }^{9}$ Especialmente os seguintes diplomas: Decreto-Lei 413/71, de 27 de Setembro (reorganizou os serviços do Ministério da Saúde e Assistência, redefiniu a política de saúde e assistência social e criou o Instituto Nacional de Saúde Dr. Ricardo Jorge); Decreto-Lei 35/73, de 6 de Fevereiro (estabeleceu um regime uniforme para todos os novos hospitais distritais que viessem a ser entregues ao Ministério da Saúde e Assistência); Decreto-Lei 162/74 (Definiu as competências dos Ministérios das Corporações e Segurança Social e da Saúde em termos de tutela administrativa das instituições particulares de assistência).

${ }^{10}$ Entrevista semi-estruturada, Lisboa, 28 de Março de 2018.
} 
revolucionários" $" 11$ liderados por Vasco Gonçalves, o rosto do radicalismo revolucionário português.

Durante o PREC, os sectores católicos temiam que o Estado nacionalizasse tudo, não apenas os hospitais. Durante o Estado Novo, apesar de algumas tropelias ditatoriais - não comparáveis às que sofreram as cooperativas e mutualidades -, as misericórdias haviam desempenhado um papel fundamental, sobretudo na área da saúde, dado que quase todos os hospitais concelhios eram geridos por misericórdias. Com as leis de nacionalização dos hospitais de 1974 e 1975, as farmácias das misericórdias também desapareceram. O clima de indignação dos provedores, mesários e autoridades eclesiásticas fez-se ouvir, colheu apoios e fez recuar o Estado.

A reparação política dos diplomas publicados durante o PREC (processo revolucionário em curso, de 25 de Abril de 1974 a 25 de Novembro de 1975) surgiu em Julho de 1979, por iniciativa do Governo de centro-direita presidido por Carlos Mota Pinto ${ }^{12}$. O processo foi difícil e sinuoso. Já no Governo de Sá Carneiro, em Fevereiro de 1980, foi publicado um diploma que revogava a gratuidade da utilização de edifícios das misericórdias onde em 1974 e 1975 se haviam instalado hospitais do Estado. O mesmo texto legal autorizava os ministros das Finanças e do Plano e dos Assuntos Sociais a aprovar a execução de verbas orçamentadas para a reparação dos prejuízos causados às misericórdias ${ }^{13}$.

Na década de noventa e nos anos recentes, as misericórdias recuperaram uma parte significativa da posição que anteriormente detinham nesta área, sendo indemnizadas pela nacionalização e auferindo rendas pelos hospitais utilizados pelo Serviço Nacional de Saúde.

Daí por diante e até hoje, as 389 misericórdias em funcionamento no país centram a sua actividade nos lares da terceira idade e infância e mantêm uma ligação forte aos poderes e elites locais. O número de misericórdias registadas e em funcionamento de 1974 a 2009 é muito estável e mantém-se ligeiramente acima das três centenas até finais do século XX.

Apesar dos obstáculos que enfrentaram nos anos do PREC, as misericórdias são as entidades mais estáveis da Economia Social, uma vez que poucas desapareceram e poucas foram fundadas até 1999.

\footnotetext{
${ }^{11}$ Entrevista semi-estruturada, Lisboa, 16 de Abril de 2018.

${ }^{12}$ Resolução 233/79, de 18 de Julho. Criava um grupo de trabalho destinado a propor as compensações que se entendem justas às Misericórdias. Essas compensações teriam como objectivo reparar as decisões resultantes da aplicação dos Decretos-Leis $n^{\circ}$ 704/74, de 7 de Dezembro, e 618/77, de 11 de Novembro, ambos sobre a nacionalização dos hospitais.

${ }^{13}$ Decreto-Lei 14/80, de 26 de Fevereiro. Assinado, além do Primeiro-Ministro Sá Carneiro, por Aníbal Cavaco Silva (ministro das Finanças e do Plano), e por João Morais Leitão (ministro dos Assuntos Sociais).
} 
Gráfico 2- Misericórdias, 1974-2009.

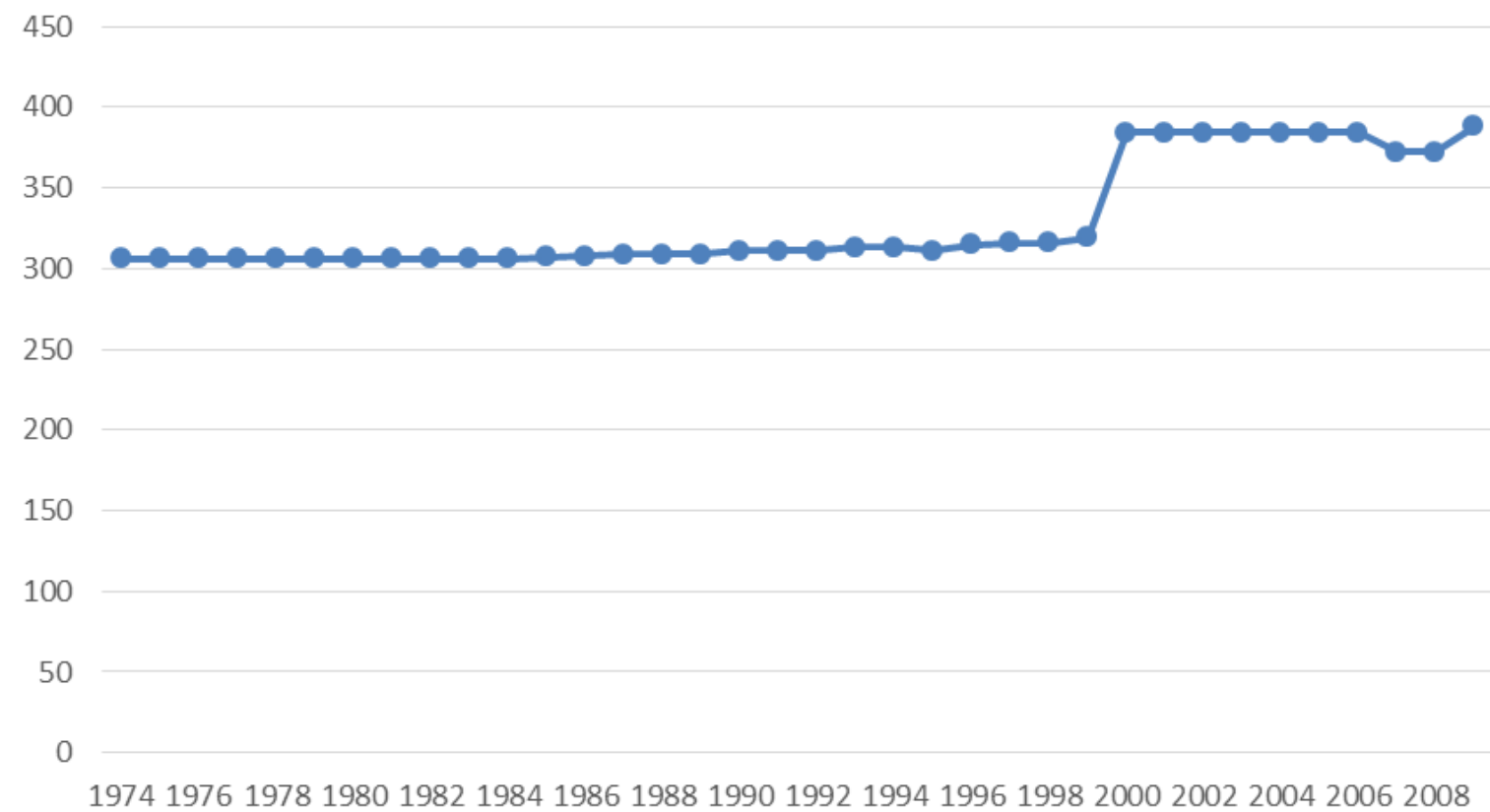

Fontes: Portugaliae Monumenta Misericordiarum (coord. José Pedro Paiva), 9. ${ }^{\circ}$ volume - Misericórdias e secularização num século turbulento (1910-2000) (dir. José Pedro Paiva; Paulo Oliveira Fontes), Lisboa, União das Misericórdias Portuguesas/ CEHR-UCP, 2010, pp. 375-387; Quem somos nas Misericórdias, Lisboa, União das Mutualidades Portuguesas, 2009. Observações: Considerámos o número de organizações registadas.

\section{AS MUTUALIDADES}

As associações mutualistas são constituídas com a finalidade de assumirem fins de proteção social complementar. Colocam à disposição dos seus associados serviços e modalidades de proteção ou de poupança garantindo ao associado, ou aos beneficiários por ele indicados, o pagamento de um benefício pela constituição de uma poupança ou pela cobertura de riscos de morte, invalidez ou velhice, conforme o plano subscrito.

Depois da Revolução de 1974, o percurso do mutualismo foi difícil e pouco articulado com a Economia Social no seu conjunto. A consagração constitucional do conceito de "instituição privada de solidariedade social" (art. 63 da Constituição de 1976) abriu caminho a uma nova era de coabitação democrática do movimento mutualista com o EstadoProvidência. No entanto, com a criação do Serviço Nacional de Saúde, em 1979, muitas mutualidades ficaram desprovidas do seu principal campo de actuação - recorde-se a figura lendária dos médicos mutualistas e o papel das farmácias adstritas a muitas mutualidades - e precisaram de reconverter os seus objectivos e estruturas.

Maioritariamente constituído por antigas associações de socorros mútuos, quando caiu o Estado Novo o mutualismo debatia-se com uma cultura muito rígida e fechada, amiúde 
secretista, que limitou o seu crescimento e o aproveitamento das oportunidades de um clima democrático $^{14}$. Em 1974 havia apenas 115 mutualidades em funcionamento no país. Na sua maioria eram associações de socorros mútuos e muitas delas montepios funerários, em regra sedeadas no norte do país. A explosão do movimento cooperativo e o papel de liderança institucional que os cooperativistas exerceram sobre o campo da Economia Social não deixou muito espaço ao movimento mutualista.

A estagnação do movimento mutualista e a sua reduzida capacidade para alcançar uma implantação semelhante aos tempos da I República foram evidências contundentes. Demasiado preso às suas memórias lendárias, não se embrenhou nas dinâmicas sociais revolucionárias e sofreu muitas vezes, por parte de sectores colectivistas e auto-gestionários, de um estigma pequeno-burguês do qual não se desembaraçou. Durante a década de oitenta, o número médio de mutualidades não excedeu as 116, praticamente as mesmas que havia em 1974.

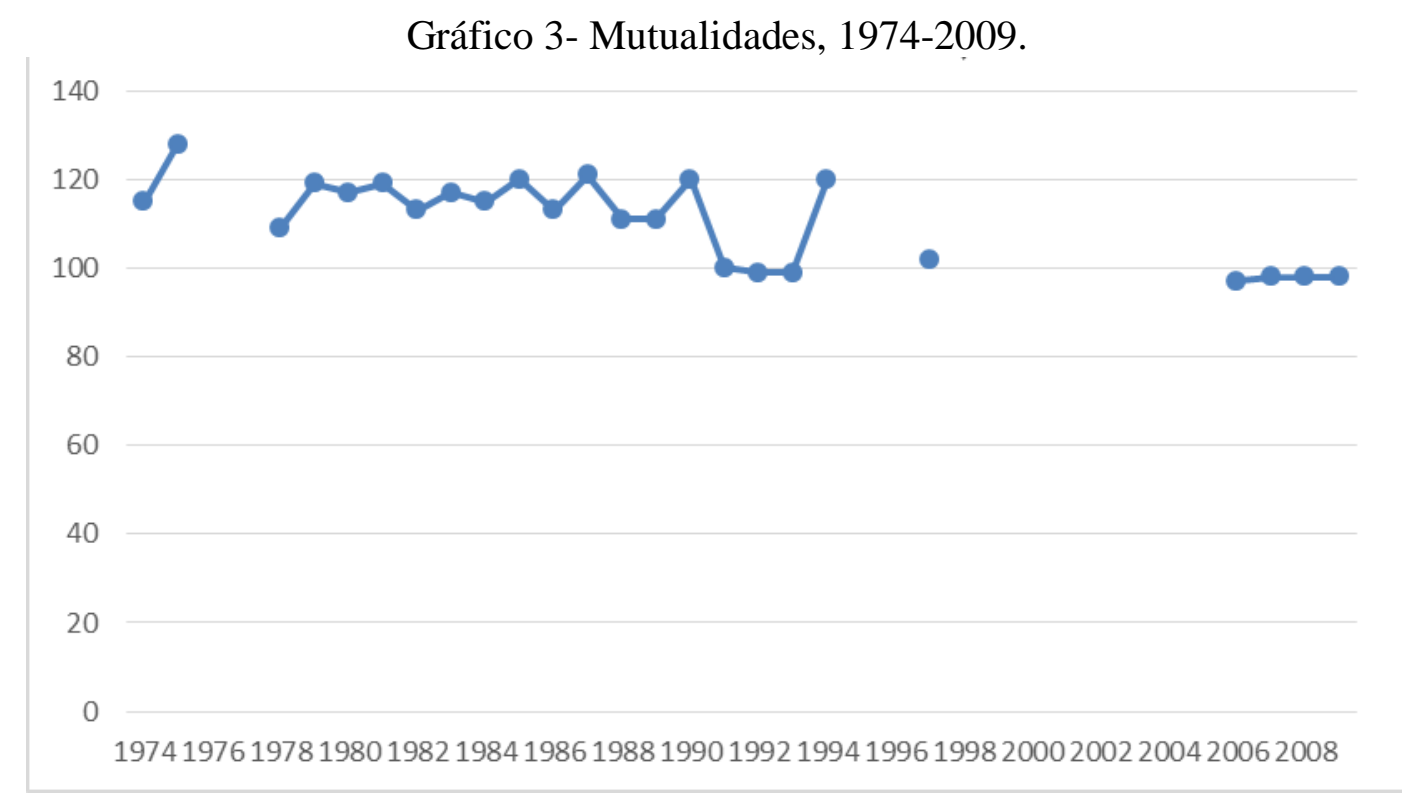

Fontes: Vasco Rosendo, O mutualismo em Portugal. Dois séculos de história e suas origens, Lisboa, Montepio Geral, 1996; Registo das Associações Mutualistas registadas na Direcção-Geral da Segurança Social, Ministério do Trabalho e da Solidariedade Social, 2008; Jorge Silveira (coord.), O mutualismo em Portugal, 1987, Lisboa, União das Mutualidades Portuguesas, 1988; Francisco Nunes; Luís Reto; Miguel Carneiro, O Terceiro Sector em Portugal, Lisboa, INSCOOP, 2001. Observações: Considerámos o número de organizações registadas.

Depois do 25 de Abril o movimento mutualista não deixou de se reorganizar, mas ficou longe da vitalidade do movimento cooperativo e da cultura operária urbana a que estivera ligado nas suas origens. Mesmo junto do funcionalismo público, dos lojistas e comerciantes a implantação das mutualidades não voltou a ser o que era.

\footnotetext{
${ }^{14}$ Entrevista com Luís Alberto Silva, Presidente da União das Mutualidades Portuguesas, Esmoriz, 24 de Abril de 2018.
} 
Nos anos posteriores, apesar dos esforços de alguns dirigentes mutualistas e das associações de maior vulto, o movimento mutualista não deu sinais de recuperação. Em representações ao Estado, o Secretariado Nacional das Associações de Socorros Mútuos insistiu muito no reconhecimento de um papel de complementaridade entre a acção médicosocial das mutualidades e o Serviço Nacional de Saúde (FERREIRA, 2000, 173-174; ROSENDO, 1996, 616-620). Para isso seriam necessários subsídios públicos que permitissem às mutualidades reestruturar serviços e equipamentos.

O Estatuto das IPSS remetia as associações de socorros mútuos para legislação específica e complementar. Essa regulamentação foi definida no Decreto 347/81, de 22 de Dezembro. Aí se reuniram disposições dispersas por vários diplomas e aí se reafirmou o papel das associações de socorros mútuos na complementaridade e melhoria dos esquemas oficiais de segurança social. Na prática, o novo regime jurídico das associações de socorros mútuos era redefinido em função do Estatuto das IPSS, que veio recompor todo o campo solidário da Economia Social.

Aquele Decreto, publicado por iniciativa do Governo de centro-direita de Francisco Pinto Balsemão, definia o campo de acção social que o próprio Estado reservava ao associativismo mutualista. A protecção à família (pensões de sobrevivência, subsídios por morte e de funeral), a protecção a pessoas atingidas por situações de incapacidade temporária para o trabalho, e aos idosos e a cidadãos com deficiência eram as atribuições mais salientes. Seguiam-se as actividades de assistência que o mutualismo sempre fizera, a exemplo da assistência médica e farmacêutica. Confirmava-se a possibilidade de as mutualidades criaram estabelecimentos e equipamentos sociais destinados à concretização dos seus fins (ROSENDO, 1996, 621). Por último, o Estado não inibia o funcionamento de caixas económicas anexas às mutualidades, dando continuidade a uma tradição associativa importante, que tinha na Caixa Económica do Montepio Geral a sua principal expressão.

Apesar da clarificação introduzida pelo estatuto das IPSS, as mutualidades haviam perdido espaço na acção social directa e pouco conquistaram desde então. Os anos oitenta foram de estagnação e de reduzido dinamismo. Se é certo que as oscilações eram mínimas de ano para ano, devido ao fecho ou reabertura desta ou daquela associação, não havia sinais de crescimento e revitalização do movimento mutualista.

As tentativas de reorganização do movimento mutualista principiaram em 1979, quando foi criada a Federação Nacional das Associações de Socorros Mútuos. A própria Federação resultou da criação de um secretariado nacional constituído a fim de posicionar as 
associações de socorros mútuos nos movimentos sociais e políticos em curso (FERREIRA, 2000, 173). Em 1984, a Federação toma a designação de União das Mutualidades Portuguesas e filia-se na Associação Internacional das Mutualidades. Nesse percurso de institucionalização prudente, as mutualidades conquistam algum reconhecimento jurídico e institucional por parte do Estado. O seu papel de "instituições complementares" do sistema de Segurança Social é reconhecido na Lei de Bases de 1984, mas no texto constitucional só a revisão de 1997 incluiria uma referência explícita às mutualidades como entidades de pleno direito do "sector cooperativo e social". Havia que incluí-las na Economia Social e nas políticas públicas.

Ainda assim, não se verificou nenhum ressurgimento do movimento mutualista. Apesar dessas expressões concretas de reconhecimento e parceria, e apesar de o estatuto das IPSS ter significado um estímulo para a reafirmação das associações mutualistas, a expressão social das mutualidades não voltou a atingir os níveis do passado. Nem quanto ao número de organizações, nem relativamente ao número de associados.

Das mutualidades existentes em 2009 - pouco mais de uma centena -, só 14 foram constituídas depois de 1990. E cerca de metade vinha do século XIX. O sector encontra-se quase monopolizado, num quadro geral de atomismo organizacional. Uma só mutualidade, o Montepio Geral, representa mais de um terço dos associados e cerca de $90 \%$ do activo líquido e dos proveitos totais. Muitas fazem apenas saúde; outras dedicam-se à previdência complementar, com ou sem caixa económica anexa (PITACAS, 2009, 29-31).

O Código Mutualista de 1990 veio atribuir o estatuto de IPSS a todas as mutualidades e regulamentou a actuação financeira das mutualidades na partilha dos riscos, segundo uma lógica de garantia. A aprovação e entrada em vigor do Código, foi um estímulo importante para o revigoramento das mutualidades na medida em que funcionou como orientador de princípios e de práticas. À época só em França havia um código das mutualidades.

Embora instituída tardiamente em Portugal, nos anos oitenta a segurança social tornou-se um espaço de competição e de complementaridades obrigando a definir o papel e os limites das organizações e iniciativas privadas, a exemplo do mutualismo. Tratando-se de um sistema de provisão essencialmente público, que assenta numa lógica de repartição entre trabalhadores activos e inactivos e nas pensões, não deixaria de ser permeável a pressões de capitalização e a um processo mais recente de "financeirização" que parece esconder intentos de privatização furtiva (RODRIGUES et alia, 2016, 143-176). A dinamização do movimento mutualista dependeria da exploração desses campos de acção social, em particular de uma 
solidariedade não colectiva.

A Lei de Bases da Segurança Social, publicada em 1984, já previa a possibilidade de os regimes profissionais complementares a criar no âmbito da Segurança Social serem geridos por associações de socorros mútuos, ou ainda "por outras pessoas colectivas criadas para o efeito e por empresas seguradoras"15. Em 1990, com a aprovação do novo Código Mutualista a possibilidade de criação de regimes profissionais complementares pelas mutualidades era concretizada através de uma clara opção privatizadora. Confirmava-se que a Lei de Bases da Segurança Social viera desafiar as organizações da Economia Social, em especial as mutualidades, para um posicionamento competitivo na área da Segurança Social. Neste como noutros marcos de evolução da Economia Social o impulso foi político e beneficiou de uma clara sedimentação ideológica.

\section{DINÂMICAS E IMPASSES DOS ANOS OITENTA E NOVENTA}

Feito o retrato da expressão institucional das entidades da Economia Social depois de 1974 e confirmada a relação dialéctica que se estabeleceu entre a consolidação das políticas sociais de cidadania e as dinâmicas do associativismo voluntário, importa observar mais de perto a construção dos marcos legislativos que teceram essa cooperação entre o público e privado. Paulatinamente, as políticas sociais da democracia portuguesa articularam previdência e assistência "reconhecendo-as como direito social de cidadania. A sociedade civil de welfare foi instrumental no alcançar deste objetivo" (BRANCO, 2017, 534).

Durante a Revolução e nos anos de turbulência económica que se lhe seguiram, marcados pela inflação, por depreciações da moeda e pelas intervenções do FMI (em 1977 e 1983), as aspirações e protestos populares em torno de direitos sociais básicos como a habitação, a saúde e a cultura tinham dado um impulso extraordinário ao movimento associativo. No entanto, desde logo no Congresso das Misericórdias de 1976, o campo da assistência particular posteriormente reunido no Estatuto das IPSS, reivindicou um reconhecimento especial do Estado e um espaço institucional autónomo.

A publicação da Lei de Bases da Segurança Social, em 1984, foi um marco fundamental da evolução das políticas sociais no contexto da democracia portuguesa que principiou em Abril de 1974 e que resultou no compromisso constitucional de 1976. Um dos aspectos mais estruturantes da Lei de Bases consistiu na forma explícita como ela veio

\footnotetext{
${ }^{15}$ Artigo $64^{\circ}$ da Lei no 28/84, de 14 de Agosto.
} 
subscrever e ampliar o papel complementar das organizações da Economia Social nas políticas sociais públicas. A europeização das políticas sociais que se registou de 1986 em diante veio aprofundar esse processo.

A Lei de Bases foi obra do governo do "bloco central" presidido por Mário Soares e nela participaram especialistas e personalidades políticas de vários quadrantes ideológicos. O texto da lei e as negociações políticas que precederam a sua aprovação parlamentar colocam em evidência diversos consensos e um claro equilíbrio entre princípios e interesses dos sectores católicos e a perspectiva de um certo humanismo laico, maioritariamente representado no Partido Socialista e em alguns sectores do PSD. A Lei de Bases definiu todo o sistema público de Segurança Social e estabilizou o papel das entidades da Economia Social na área abrangente da acção social.

A repartição de responsabilidades entre o Estado e o "sector cooperativo e social" - leia-se, a Economia Social - definido na Constituição foi equilibrada e consequente. O artigo $66^{\circ}$, art. $1^{\circ}$, da Lei de Bases exprime esse compromisso sem hesitações: "O Estado reconhece e valoriza a acção desenvolvida pelas instituições particulares de solidariedade social na prossecução dos objectivos da segurança social”. De fora dessa lógica de complementaridade ficava o sector da saúde. Criado em 1979, o Serviço Nacional de Saúde consagrou direitos sociais de provisão pública e de cobertura universal.

A Constituição de 1976 já abrira caminho a um forte desenvolvimento do subsector solidário da Economia Social, em especial de uma rede de serviços e de equipamentos sociais. Numa opção clara e explícita, a Lei de Bases da Segurança Social abandona o papel preponderante do Estado no domínio da assistência social e entrega boa parte dessas responsabilidades às IPSS. Na sequência dos entendimentos com a hierarquia eclesiástica e das negociações para a revisão da Concordata assinada com a Santa Sé $^{16}$, os governos constitucionais parecem ter beneficiado a rede de instituições sociais ligadas à Igreja Católica em detrimento dos movimentos sociais de base operária e das organizações enraizadas nos territórios urbanos e suburbanos.

O Estatuto das IPSS aprovado em 1979 começara a ser preparado em meados de 1977. Elaborado um extenso projecto de lei sobre o estatuto da "assistência particular",

\footnotetext{
16 O Protocolo Adicional à Concordata de 1940 assinado em 15 de Fevereiro de 1975 incidiu sobretudo no direito ao divórcio dos casais católicos. Isso não quer dizer que as negociações e o entendimento diplomático alcançado não tenham diminuído as apreensões que a Revolução portuguesa criara em Roma abrindo um período de bom entendimento entre os governos constitucionais portugueses e a Santa Sé. Evitando os excessos do jacobinismo republicano, Mário Soares teve um papel decisivo nesse equilíbrio.
} 
pronunciou-se a Conferência Episcopal Portuguesa. O projecto de lei conheceu aí profundas alterações e foi devolvido para consulta às dezoito maiores instituições de assistência (CONGRESSO, 1980, 67-74). Pronunciou-se ainda a União das Misericórdias Portuguesas, cuja existência era recente, mas que se encontrava em pleno funcionamento. Não por acaso, o segundo estatuto das IPSS, aprovado em 1983, concedeu uma situação especial a todas as instituições da Igreja Católica - aquelas que são erigidas por Direito Canónico - aplicando-selhes o regime concordatário, fossem os seus fins predominantemente religiosos, fossem elas votadas à assistência.

\section{CONCLUSÕES}

No clima turbulento das crises económicas dos anos setenta e oitenta que abriram caminho ao neoliberalismo, muitos países voltaram a experimentar elevadas taxas de desemprego, problema que regressou ou persistiu nos anos noventa, já no contexto da globalização. Essa sombria realidade e o recuo da protecção social assegurada pelo Estado explicam o renovado interesse pela Economia Social e o seu revigoramento de práticas e organizações. Se nos anos setenta os serviços sociais produzidos por organizações da Economia Social ofereciam alternativas aos serviços públicos de origem estatal, nos anos noventa, em países como Portugal, França e Espanha esses serviços colectivos de natureza particular ou associativa já serviam para satisfazer necessidades negligenciadas ou difíceis de cobrir pelo Estado (BOUCHARD e RICHEZ-BATTESTI, 2008, 5-13).

A crítica social às grandes concentrações capitalistas, a valorização das pequenas empresas e a redescoberta das identidades laborais de âmbito local tornaram evidentes a existência de um "terceiro sector" da vida económica, nem público nem privado, mas crítico ou alternativo a uma economia capitalista cada vez mais aprisionada nos mercados financeiros globais. A importância social dessa "outra economia", no emprego e na protecção social, começou a ser reconhecida e não tardou que os dirigentes e intelectuais que defendiam uma Economia Social revigorada ou um "terceiro sector" reclamassem direitos de institucionalização e um reconhecimento público inequívoco.

Levantou-se assim, primeiro em França e depois noutros países, a questão muito actual do direito das organizações identificadas com a Economia Social a subvenções públicas e a doações particulares. Formas institucionais de cooperação contratualizada começam a surgir em alguns países. Tornam-se uma prática comum na década de oitenta, nomeadamente 
onde houve necessidade de conjugar uma tradição de assistência muito vinculada à Igreja Católica e sistemas de segurança social que dificilmente podiam crescer mais. Esse problema prático, hoje muito debatido, abriu uma discussão importante sobre os novos estatutos e perfis das associações e colocou novos horizontes à velha questão das relações entre o público e o privado nos domínios da previdência e da assistência.

Participando de uma aspiração geral da sociedade, nos anos setenta e oitenta a Economia Social encontrou um novo alento e conheceu progressos apreciáveis quer no campo teórico e académico, quer nas comunidades e territórios locais. Essas dinâmicas foram variáveis de país para país e as tradições organizativas da Economia Social tiveram grande influência no desenho das leis. Os equilíbrios de poder contaram muito nos arranjos institucionais.

Em Portugal, as águas começaram a separar-se com nitidez durante o período revolucionário de 1974-75, mas foi o sistema público e universal de segurança social que ofereceu às instituições particulares de assistência um papel de complementaridade difícil de substituir através de um sistema único no qual o Estado detivesse toda a responsabilidade sobre as diversas formas de "acção social directa". A delimitação de territórios foi uma forma de criar condições institucionais para uma crescente convergência entre o campo público da previdência e o protagonismo privado (a solidariedade colectiva de iniciativa particular) no domínio da assistência. Como concluiu Rui Branco, a estabilização de um sistema de provisão de serviços sociais pela sociedade civil em parceria com as instituições do Estado-Providência acabou por configurar "um regime neo-corporativo de policy-making" (BRANCO, 2017, $535)$.

Em Portugal, no novo ciclo de vida que a Economia Social conheceu a seguir ao 25 de Abril o sector social desenvolveu-se em aliança com as organizações e iniciativas da sociedade civil. A definição do estatuto das IPSS, em 1979 e 1983, uma originalidade da Economia Social portuguesa, permitiu aprofundar essa cooperação afirmando um princípio mais efectivo de subsidiariedade nas políticas sociais.

Se durante a ditadura de Salazar e Caetano as políticas sociais haviam sido eminentemente assistencialistas e obcecadas com a "ordem pública", tendo o Estado assumido um papel apenas supletivo, a Constituição de 1976 e o sistema de segurança social que dela emanou atribuíram claras responsabilidades ao Estado. Prevaleceu uma concepção de cidadania social e de solidariedade democrática assente na redistribuição de rendimentos e na garantia de mínimos sociais (JOAQUIM, 2015, 7-16). 
Através das revisões constitucionais de 1989 e de 1997 o sector cooperativo destacado na Constituição de 1976 deu lugar ao actual "sector cooperativo e social". A polissemia organizativa da Economia Social e os diversos campos que nela coabitavam, cada entidade com o seu património de valores, parece ter obrigado os legisladores a acolher, além dos subsectores comunitário e autogestionário anteriormente incluídos no sector público, um sector solidário. Na prática, era preciso incluir o mutualismo e as entidades com estatuto de IPSS na galáxia institucional das diversas entidades da Economia Social.

\section{REFERÊNCIAS}

ANDRADE, Inácio Rebelo de, O Itinerário Cooperativo Português, Évora, Universidade de Évora, 1990.

BARRETO, António, Anatomia de uma Revolução. A Reforma Agrária em Portugal, 19741976, Lisboa, Publicações Dom Quixote, 2017.

BRANCO, Rui, "Entre Bismarck e Beveridge: sociedade civil e Estado providência em Portugal (1960-2011)", in Análise Social, n. ${ }^{\circ} 224$, (3. $\left.^{\circ}\right), 2017$, pp. 534-558.

BOUCHARD, Marie J.; RICHEZ-BATTESTI, Nadine, "L'évaluation de l'économie sociale et solidaire: une perspective critique et internationale", in Économie et Solidarités, vol. 39, n 1, 2008.

CASTEL, Robert, Les metamorfoses de la questionsociale. Une chronique du salariat, Paris, Gallimard, 2012.

CATTANI, Antonio David; LAVILLE, Jean-Louis; GAIGER, Luiz Inacio.; HESPANHA, Pedro (orgs.), Dicionário Internacional da Outra Economia, Coimbra, Almedina/CES, 2009.

II Congresso das Instituições Privadas de Solidariedade Social, Porto, ed. União das IPSS, 1980.

FARIA, Maurício Sardá de, Autogestão, Cooperativa, Economia Solidária: avatares do trabalho e do capital, Florianópolis, Editoria Em Debate, 2011.

FERREIRA, Ana Rita; CAROLO; Daniel; PEREIRA, Mariana Trigo; SILVA, Pedro Adão e, "Fundamentos constitucionais da protecção social - continuidades e rupturas", Sociologia, Problemas e Práticas, $\mathrm{n}^{\circ}$ especial, 2016, pp. 71-97.

FERREIRA, Sílvia, O papel das organizações do terceiro sector na reforma das políticas públicas de protecção social. Uma abordagem teórico-histórica, Coimbra, Tese de Mestrado em Sociologia apresentada à Faculdade de Economia da Universidade de Coimbra, 2000.

FRIEDDEN, Jeffrey, Global Capitalism: Its Fall and Rise in the Twentieth Century, New 
York, Norton \& Company, 2006.

GARRIDO, Álvaro, “A institucionalização do social no Estado Novo português. Previdência corporativa e seguros sociais voluntários", in Revista Estudos Históricos, n 64, 2018, pp. 21 44.

Cooperação e Solidariedade. Uma história da Economia Social, Lisboa, Tinta da China, 2016.

GUESLIN, André, L'Invention de L'Économie Sociale. Idées, pratiques et imaginaires coopératifs et mutualistes dans la France du XIXesiècle, Paris, Economica, 1998.

HIEZ, David; LAVILLUNIÈRE, Eric (dir.), Vers une théorie de l'Économie Sociale et Solidaire, Bruxelles, Larcier, 2013.

HORNE, Janet, Le Musée Social. Aux origines de l'État Providence, Paris, Belin, 2004.

JOAQUIM, Cláudia, O terceiro sector e a protecção social: Que modelo para Portugal?, Lisboa, Dissertação de Mestrado em Políticas Públicas apresentada ao ISCTE - Instituto Universitário de Lisboa, 2015.

LAVILLE, Jean-Louis, A Economia Social e Solidária. Práticas, Teorias e Debates, Coimbra, Almedina/CES, 2018.

LEITE, João Salazar, Enquadramento Histórico-Social do Movimento Cooperativo, Lisboa, INSCOOP, 1994.

LIPIETZ, Alain, Pour le tiers secteur. L'économie sociale et solidaire: pourquoi et comment, Paris, la Découverte/ La Documentation française, 2001.

MEIRA, Deolinda, "A Lei de Bases da Economia Social Portuguesa; do projecto ao texto final”, in Revista Jurídica, no 24, 2013, pp. 1-32.

NAMORADO, Rui, O essencial sobre Cooperativas, Lisboa, Imprensa Nacional-Casa da Moeda, 2013.

- "Renovar os quadros jurídicos da Economia Social?", in Oficina do Centro de Estudos Sociais, $\mathrm{n}^{\circ}$ 293, 2007, pp. 10-12.

PAIVA, José Pedro (coord.), Portugaliae Monumenta Misericordiarum, $8 .^{\circ}$ e $9 .^{\circ}$ volumes, Lisboa, União das Misericórdias Portuguesas/ CEHR-UCP, 2010.

PEREIRA, Miriam Halpern, "As origens do Estado Providência em Portugal: as novas fronteiras entre o público e o privado", in Ler História, no 37, 1999, pp. 45-61.

PITACAS, José Alberto, Utilidade Social e Eficiência no Mutualismo, Lisboa, Tese de Mestrado em Economia e Política Social apresentada ao Instituto Superior de Economia e Gestão da Universidade de Lisboa, 2009. 
RODRIGUES, João Rodrigues; SANTOS, Ana Cordeiro; TELES, Nuno, A financeirização do capitalismo em Portugal, Coimbra, Conjuntura Actual Editora, 2016.

ROSENDO, Vasco, O mutualismo em Portugal: dois séculos de história e suas origens, Lisboa, Montepio Geral/ Multinova, 1996.

SÁ, Isabel dos Guimarães; LOPES, Maria Antónia, História Breve das Misericórdias Portuguesas, Coimbra, Imprensa da Universidade de Coimbra, 2008.

SINGER, Paul, Ensaios sobre Economia Solidária, Coimbra. Almedina, 2018.

VARELA, Raquel e PIÇARRA, Constantino, "A reforma agrária nos campos do sul de Portugal (1975): uma revolução na revolução”, in Estudos Ibéricos, Porto Alegre, vol. 42, n 3, Setembro-Dezembro de 2016, pp. 1189-1218.

Recebido em: Agosto de 2018 Aprovado em: Setembro de 2018 